\title{
A ATUAÇÃO DO PEDAGOGO NO ESPAÇO DE RECURSOS HUMANOS
}

\section{Priscila Pinheiro Monzato}

MBA em Tecnologia da Informação e Gestão de Projetos - Especialista em Educação Corporativa - Pedagoga Facilitadora de grupos de Preparação para a Aposentadoria e Palestrante no tema de Líder Coach Superintendência de Recursos Humanos (SRH) - Universidade do Estado do Rio de Janeiro $\triangle$ pripmz@gmail.com/secap@srh.uerj.br

Exercitar a prática de olhar para o nosso cotidiano, descrever e analisar nossas ações é uma experiência imensamente rica para o aprimoramento das atividades e melhor percepção do cenário. Portanto, aceito o desafio de refletir e de contribuir com novos olhares para os interessados no assunto.

A Pedagogia é a ciência que tem como objetivo a reflexão, a sistematização e a análise do processo educativo. O Pedagogo tem o papel de procurar estratégias e metodologias que garantam uma melhor aprendizagem e apropriação de conhecimentos, tendo como alvo principal gerar mudanças no comportamento das pessoas de modo que estas melhorem tanto a qualidade da sua atuação profissional quanto pessoal. Também pode desenvolver trabalhos para motivá-las, com o objetivo de aperfeiçoar a produtividade humana. Hoje, é importante pautar as propostas de treinamento sob a ótica da heutagogia, que é mediada por recursos tecnológicos e centrada nas necessidades do participante, quem determina o que e como sua aprendizagem deve ocorrer. Para lidar com adultos é extremamente pertinente valorizar suas experiências pessoais e a aplicabilidade do aprendizado no dia a dia, bem como considerar a necessidade de rapidez na assimilação de conhecimento e o aprimoramento de habilidades. Por isso, enquanto Pedagoga atuante no setor de Recursos Humanos eu devo estar atenta às mudanças de cenário, às inovações e me preocupar em oferecer os cursos de desenvolvimento focado nas necessidades dos servidores.

O Pedagogo é o profissional responsável pelo ato de condução do saber, é quem pode transmitir, com propriedade, as técnicas de levantamento de necessidades, planejamento, elaboração e mensuração dos programas e resultados de treinamento. A atuação deste profissional, por muito tempo se restringiu aos espaços da sala de aula, mas ultimamente esse.

Percebo que a minha atuação como Pedagoga localizada na Superintendência de Recursos Humanos no Setor de Capacitação tem um papel central dentro desta Universidade com perfil tradicional de ensino como a UERJ, que é a iniciativa de propor metodologias 
diferenciadas. Como por exemplo, atualmente, minha prática está sendo agregada com os conhecimentos e ferramentas de Coaching uma metodologia relativamente nova no Brasil e que visa ao desenvolvimento global do ser humano e à maximização dos pontos fortes em busca do alcance de metas, gerando assim ações potencializadoras para dentro da Universidade. Desta forma, sempre que me proponho a dar treinamentos, agrego os conhecimentos de Pedagogo com o Coaching e percebo um resultado melhor. Seja em cursos de capacitação, na modalidade presencial e à distância, eventos para difundir conhecimento, como palestra ou no Programa de Preparação para Aposentadoria identifico como oportunidade para desenvolver a performance dos servidores e causar impacto na sociedade.

A minha responsabilidade vai desde a fase inicial do planejamento, perpassando pelo acompanhamento dos cursos até o final, quando as avaliações de reação são aplicadas e também como instrutora de alguns cursos. Busco sempre atuar de forma congruente à minha área de conhecimento e também considero os olhares dos outros profissionais que já atuaram neste cenário relacionado aqui como, por exemplo, o psicólogo, o administrador, o assistente social, pois reconheço que agregam imensamente a minha prática.

Ressalto que é de extrema importância para o Pedagogo que busca atuar na área de Recursos Humanos, ter atitude de buscar o aprimoramento constante dele próprio para que possa implantar as devidas inovações nos conteúdos e nas propostas de trabalho a serem oferecidas para os servidores. Como também ter um perfil voltado para o bom atendimento das pessoas e de realização de eventos que contemplem a integração dos mesmos. Nada mais coerente do que trabalhar em um setor que cuida da capacitação dos servidores é estar capacitado de forma bem atualizada e gostar de lidar com pessoas.

Em 4 anos de experiência no Serviço de Capacitação já percebi mudança de consciência e de comportamento em muitos servidores que passaram pelos nossos cursos e, como consequência, não só a Universidade é impactada por esses benefícios, como também a sociedade em geral. Atualmente, o quantitativo que atendemos é menor do que o que pretendemos atender com o advento da Lei 6701/2014, que reformula o plano de cargos, carreiras e remuneração do quadro de pessoal dos servidores técnico-administrativos da UERJ e, assim, reforça ainda mais a importância da capacitação. Assim, um dos principais profissionais para atuar nesse espaço é o Pedagogo, cujo perfil deverá ser focado para cursos que atendam às necessidades da demanda, ter conhecimentos atualizados para construir um formato de Capacitação motivador e poder validar o impacto de todo o aprendizado e satisfação gerados nos servidores. 
Portanto, depois dessa prática reflexiva, continuo confirmando que sou apaixonada pelo meu trabalho, que independentemente de reconhecimentos externos percebo a importância do meu papel nesse cenário e dos resultados extraordinários que podem surgir devido ao estímulo contínuo ao desenvolvimento dos servidores.

\section{REFERÊNCIAS}

CASSIMIRO, Patrícia Rocha. Pedagogia Empresarial.

Disponível em: 〈http://www.infoescola.com/profissoes/pedagogia-empresarial/>. Acesso em: 02 jun. 2015.

HAMZE, Amélia. Professor Pedagogo.

Disponível em: <http://educador.brasilescola.com/trabalho-docente/professor-pedagogocondutor-de-criancas-a-empreen.htm>. Acesso em: 02 jun. 2015.

PAZ, Charlyne Pinheiro da; CARVALHO, Taise Neves. O RH e a Pedagogia Empresarial. Disponível em: 〈http://www.pedagogia.com.br/artigos/rhpedagogiaempresarial/>. Acesso em: 02 jun. 2015. 